\title{
A Comparative Evaluation of Polystyrene Divinylbenzene Copolymer HPLC Columns on the Chromatographic Performance of the Compendial Method for Doxycycline Hyclate Capsules: Implications for Method Implementation of a Medical Countermeasure Medication
}

\author{
Firat Yerlikaya, Adil Mohammad, Patrick J. Faustino, Mansoor A. Khan, Saeed R. Khan \\ Division of Product Quality Research, Office of Testing and Research, Office of Pharmaceutical Quality, Center \\ for Drug Evaluation and Research, Food and Drug Administration, Silver Spring, MD, USA \\ Email: saeed.khan2@fda.hhs.gov
}

Received 5 June 2015; accepted 29 August 2015; published 2 September 2015

Copyright (C) 2015 by authors and Scientific Research Publishing Inc.

This work is licensed under the Creative Commons Attribution International License (CC BY).

http://creativecommons.org/licenses/by/4.0/

(c) (i)

Open Access

\begin{abstract}
The purpose of this study was to evaluate the impact of polystyrene divinylbenzene copolymer HPLC columns on the chromatographic performance of the USP compendial method for doxycycline hyclate. The compendial method was implemented based on the assessment of the chromatographic performance of six USP defined L21 polystyrene divinylbenzene HPLC columns. Modifications to the method were based on USP $<621>$ for chromatography. The method was validated for the determination of doxycycline hyclate and its impurities in commercially available drug products. A number of different polystyrene-divinylbenzene columns were tested and failed to provide selectivity for the resolution of doxycycline and its impurities. Separation was optimally achieved on an Agilent PLPR-S column $(250 \times 4.6 \mathrm{~mm}, 8 \mu \mathrm{m})$ by using an Agilent 1260 series HPLC system. Doxycycline hyclate and its impurities were eluted isocratically at a flow rate of $1 \mathrm{~mL} / \mathrm{min}$ with mobile phase and detected at $270 \mathrm{~nm}$. The column temperature was maintained at $60^{\circ} \mathrm{C}$. The method was validated according to USP category I requirements for Assay. Validation acceptance criteria were met in all cases. The analytical range for doxycycline hyclate was $50-250 \mu \mathrm{g} / \mathrm{mL}$ and the linearity was $r^{2}>0.999$ over three days. The method was determined to be specific. Both accuracy $(95.1 \%-102.4 \%)$ and precision $(0.50 \%-4.8 \%)$ were established across the analytical

How to cite this paper: Yerlikaya, F., Mohammad, A., Faustino, P.J., Khan, M.A. and Khan, S.R. (2015) A Comparative Evaluation of Polystyrene Divinylbenzene Copolymer HPLC Columns on the Chromatographic Performance of the Compendal Method for Doxycycline Hyclate Capsules: Implications for Method Implementation of a Medical Countermeasure Medication. Journal of Analytical Sciences, Methods and Instrumentation, 5, 23-34. http://dx.doi.org/10.4236/jasmi.2015.53003
\end{abstract}


range for low, intermediate and high QC concentrations. Method applicability was demonstrated by analyzing marketed products of doxycycline hyclate, in which results showed potency meeting USP acceptance criteria. In conclusion, this study described the remarkable differences in selectivity that were encountered during the implementation phase for the compendial methods for doxycycline and its impurities in marketed products and it could be used in the future to assss the product quality of doxycycline hyclate capsules stored in the National stockpiles.

\section{Keywords}

Doxycycline, 4-Epidoxycycline, 6-Epidoxycycline, Metacycline, Polystyrene-Divinylbenzene

\section{Introduction}

Doxycycline hyclate is a bacteriostatic tetracycline antibiotic and is prescribed primarily for the treatment of urinary, respiratory, and gastrointestinal tract infections. It is a first response medication indicated for Acute Radiation Syndrome (ARS). The efficient implementation of compendial methods is essential for the quality assessment of medical counter-measure medications like doxycycline that have been stockpiled for emergency use. With the dramatic increase in the number of marketed columns from vendors with-in the required column packing categories (i.e., L21 for doxycycline), the efficient implementation of compendial methods has become more challenging. For example, for USP packing L1 (i.e., C-18) there are more than 200 columns available on the market. To select a column that will allow for the efficient implementation of a compendial method, the analyst must try to decide among type A or B silica, chemical selectivity, particle size, particle shape (i.e. spherical or irregular), steric interactions, and hydrophobicity to name just a few factors that can impact the performance of the liquid chromatographic method. In general, because of these differences, small changes in $\mathrm{pH}$ or the organic component of the mobile phase can result in major differences in the hydrophobicity of the packing and thus the selectivity. For columns such as divinylbenzene that contain the copolymer, the degree of cross-linking can significantly affect the hydrophobic interactions and the overall selectivity. Because the nature of the polymer in terms of side chains or cross-linking is generally not well described, the selection of different L21 columns for compendial methods can be challenging and in many cases can be trial and error. The purpose of this study is to identify factors that can impact the efficient implementation of compendial methods for stockpiled drug products such as doxycycline.

An essential first step in the implementation of a chromatographic method is an understanding of the chemical nature for the molecule. Doxycycline hyclate is freely soluble in water $(50 \mathrm{mg} / \mathrm{ml})$ and has a $\log P$ value of -1.90 [1]. The aqueous solution, containing 1\% doxycycline hyclate, has a pH of 2-3 and a pKa of 3.05 [2]. Doxycycline hyclate is a Biopharmaceutical Classification System (BCS) Class I drug substance exhibiting high solubility and permeability [1]. Its molecular formula and weight are $\mathrm{C}_{22} \mathrm{H}_{25} \mathrm{ClN}_{2} \mathrm{O}_{8}, 1 / 2 \mathrm{C}_{2} \mathrm{H}_{6} \mathrm{O}, 1 / 2 \mathrm{H}_{2} \mathrm{O}$ and 512.94, respectively (Figure 1). Commercially, it is available as capsules, delayed release capsules, tablets, delayed release tablets, periodontal systems and injectable dosage forms with strengths from $20 \mathrm{mg}$ to $200 \mathrm{mg}$ (equivalent to the free base of doxycycline).

There are many papers in the literature describing the HPLC analysis of doxycycline hyclate in pharmaceutical dosage forms, using different mobile and stationary phases [3]-[13]. The first compendial method was published by the European Pharmacopoeia in 1989 and later it has been adopted by the British Pharmacopoeia and United States Pharmacopeia for relevant monographs [14]-[17]. Current United States Pharmacopeia doxycycline related monographs require using a polystyrene-divinylbenzene (PSDVB) copolymer stationary phase, which is known for its good stability under extreme $\mathrm{pH}$ conditions and very good selectivity for the epimers of tetracyclines [18]. In this compendial method, an ion-pair agent, tetrabutylammonium hydrogen sulfate has been adopted.

Ion-pair reagents are a standard approach for modifying the mobile phase, generally to reduce tailing and enhance resolution. It is thought that they are electrostatically adsorbed onto the surface of the column and the retention of the analytes is probably based on the interaction with the hydrophobic parts of the ion-pair agent [19] [20]. The method provides an accurate and reproducible determination of doxycycline hyclate and their impurities in pharmaceutical samples. 


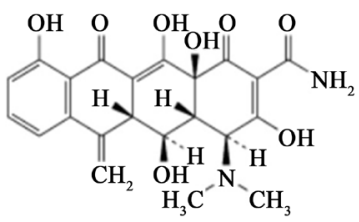

Metacycline

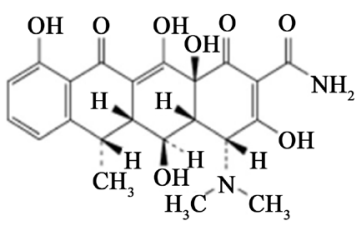

4,6-epidoxycycline

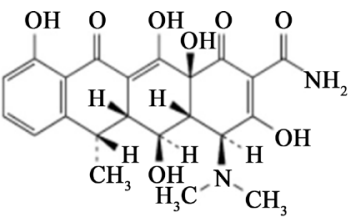

6-epidoxycycline

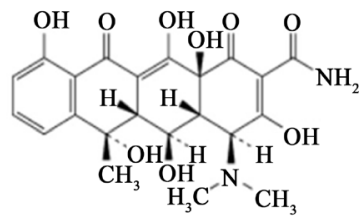

Oxytetracycline
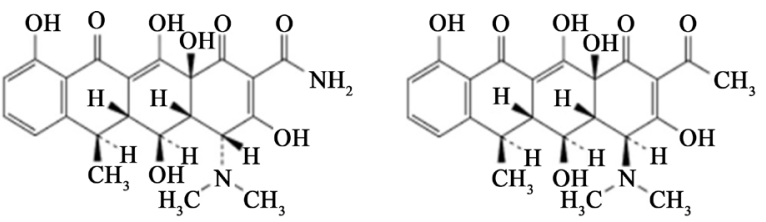

4-epidoxycycline

2-acetyl-2-decarbamoyldoxycycline

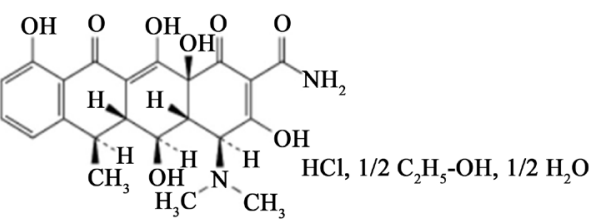

Doxycycline hyclate

Figure 1. Molecular structure of doxycycline hyclate and its related substances.

Tetracycline and its analogs such as doxycycline are generally amphoteric, highly polar substances with an isoelectric point between four and six and have a tendency to form chelates. Therefore it is important to chromatographically control: 1) ion-exchange and hydrophobic interactions of these molecules with stationary phases by choosing a mobile phase at a $\mathrm{pH}$ in accordance with the dissociation of the analytes; 2 ) interaction of metals by addition of chelating agents to the mobile phase, such as disodium edentate; 3) enhancing adsorption of the analytes onto the column surface by addition of amines to the mobile phase, such as tetrabutylammonium hydrogen sulfate [6] [21] [22].

Compendial monographs for doxycycline hyclate require using a polystyrene-divinylbenzene copolymer packing material with a column length of $250 \mathrm{~mm}, 4.6 \mathrm{~mm}$ internal diameter, $10 \mathrm{~nm}$ pore size and $8 \mu \mathrm{m}$ particle size as the stationary phase. Different types of PSDVB columns were previously tested by Hoogmartens et al. [14] and they found that PLRP-S and PRP-1 columns generated similar results; however, there was no study identified in the literature comparing the influence of different PSDVB packing materials from various vendors on the chromatographic separation of doxycycline analogs. In this study, we tested different polystyrene-divinylbenzene copolymer columns in order to evaluate the influence of various columns on the chromatographic separation of doxycycline analogs by using compendial testing procedures for assay and impurities of doxycycline hyclate capsules. The specific purpose of this study was to clearly understand the impact of column characteristics such as particle size, column length and packing source on the efficient implementation of the compendial methodology for assay. The overarching goal is to help to best ensure that regulatory authorities and scientists throughout the world can efficiently implement compendial methodology to assess the quality of doxycycline or other medical counter measure antibiotics.

\section{Materials and Methods}

\subsection{Materials}

Doxycycline hyclate, metacycline hydrochloride and 6-epidoxycycline certified reference standards were purchased from the United Sates Pharmacopeial Convention (Rockville, MD). The 4-epidoxycycline reference standard was purchased from Toronto Research Chemicals Inc. (Toronto, Canada). The doxycycline hyclate capsule samples were received from the FDA, Center for Drug and Evaluation Research's (CDER) Office of Counter-Terrorism and Emergency Coordination (OCTEC). 2-methylpropan-2-ol, disodium edetate, sodium hydroxide, and tetrabutylammonium hydrogen sulfate were purchased from Sigma-Aldrich (St. Louis, MO). Hydrochloric acid and potassium phosphate monobasic were purchased from Fischer Scientific (Fairlawn, NJ). Deionized (DI) water was purified in-house to $18 \mathrm{M} \Omega$ of electrical resistivity (Millipore, Milford, MA). All reagents were HPLC grade.

\subsection{Chromatographic Conditions and Evaluation of Columns}

An Agilent Technologies 1260 Series high-performance liquid chromatograph consisting of an-online degasser, a binary pump, an auto-sampler, a thermostatic column compartment, and a variable wavelength detector was 
used for the study. The injection volume was $20 \mu$ l. The column thermostat temperature was maintained at $60^{\circ} \mathrm{C}$ and the detector wavelength was set at $270 \mathrm{~nm}$. Total analysis run time was $30 \mathrm{~min}$. The flow rate of the mobile phase was $1.0 \mathrm{ml} / \mathrm{min}$ using isocratic elution conditions.

\subsubsection{System Suitability}

Using reference solution (f), containing doxycycline hyclate, metacycline hydrochloride, 6-epidoxycycline hydrochloride, and 4-epidoxycycline hydrochloridethe resolution factor between metacycline (RRT = 0.8) and 6epidoxycycline (RRT $=0.85$ ) must be at least 1.25 and the resolution factor between 6-epidoxycycline and doxycycline (RT $=17 \mathrm{~min})$ must be at least 2.0. If necessary the content of 2-methylpropan-2-ol in the mobile phase was adjusted. The repeatability of peak area $(<2 \%$ RSD), capacity factor $(>1.0)$, theoretical plates $(>2000)$, peak symmetry $(>0.5)$, and USP tailing factor $(<2.0)$ was calculated based on six replicate injections.

\subsubsection{Limits}

For impurities, using test solution (a) the area of any peak corresponding to metacycline, and 6-epidoxycycline was not greater than the area of the corresponding peak in the chromatogram obtained with reference solution (e) (2\%, with reference to doxycycline hyclate) and the area of any other secondary peak is not greater than 0.25 times the area of the peak corresponding to 6-epidoxycycline in the chromatogram obtained with reference solution (e) $(0.5 \%$, with reference to doxycycline hyclate).

\subsubsection{Assay}

For assay, the content anhydrous doxycycline in test solution (b) was calculated using the declared content of anhydrous doxycycline in the doxycycline reference solution (g). Assay must be between $95.0-105.0 \mathrm{mg} / \mathrm{capsule}$ ( $95.0 \%$ to $105.0 \%$ of the stated amount). The formula for the calculations is shown below:

$$
\text { Assay }=\left(r_{U} / r_{S}\right) \times\left(C_{S} / C_{U}\right) \times P
$$

$r_{U}$ : Peak response from the test solution (b)

$r_{S}$ : Peak response from the reference solution (g)

$C_{S}$ : Concentration of reference solution $(\mathrm{g})(\mathrm{mg} / \mathrm{ml})$

$C_{U}$ : Concentration of test solution (b) $(\mathrm{mg} / \mathrm{ml})$

$P$ : Potency of doxycycline in USP Doxycycline Hyclate RS (mg/mg)

The columns that were tested in the scope of this study are shown in Table 1.

Each of these columns was pre-conditioned with 20 column volumes of the actual mobile phase and equilibrated prior to testing. In order to evaluate the performance of the columns, a reference solution, which contains $128 \mu \mathrm{g} / \mathrm{ml}$ of doxycycline hyclate, $32 \mu \mathrm{g} / \mathrm{ml}$ of metacycline hydrochloride, $48 \mu \mathrm{g} / \mathrm{ml}$ of 6-epidoxycycline hydrochloride, and $12 \mu \mathrm{g} / \mathrm{ml}$ of 4-epidoxycycline hydrochloride in $0.01 \mathrm{M}$ hydrochloric acid was injected to the columns and the obtained chromatograms were evaluated for chromatographic separation and efficiency.

\subsection{System Suitability Testing and Validation of the Compendial Analytical Method}

System suitability was conducted daily and the analytical method was validated according to the United States Pharmacopeia requirements for compendial methods using the column described in the European Pharmacopoeia, United States Pharmacopeia and British Pharmacopoeia [15].

Table 1. Polystyrene-divinylbenzene copolymer columns that were tested.

\begin{tabular}{cccccc}
\hline Manufacturer & Packing material & Particle size $(\mu \mathrm{m})$ & Length $(\mathrm{mm})$ & Internal diameter $(\mathrm{mm})$ & Pore size $(\mathrm{nm})$ \\
\hline Agilent Technologies & PLRP-S & 8 & 250 & 4.6 & 10 \\
Agilent Technologies & PLRP-S & 5 & 250 & 10 & 4.6 \\
Agilent Technologies & PLRP-S & 3 & 30 & 4.6 & 4.6 \\
Waters & Styragel HR DMF & 5 & 300 & 4.6 & 10 \\
Phenomenex & Phenogel & 5 & 250 & 4.6 & 10 \\
Hamilton & PRP-1 & 5 & & \\
\hline
\end{tabular}

N/A*: Information is not available through the manufacturer. 


\subsection{Validation of the Compendial Analytical Method}

The analytical method for doxycycline was validated according to the requirements of United States Pharmacopeia general chapter $<1225>$ for assay. A linear calibration model was generated as a least squares fit of measured peak areas to known calibration sample concentrations. The resulting weighted linear function, $y=m x$ $+b$, was used to calculate the concentration of doxycycline quality control standards from assayed peak areas. Accuracy and precision are calculated from the concentration data and the peak response of the quality control standards using the weighted linear function. Analytical range is established by determining that the accuracy, precision and linearity are acceptable over the analytical range according to the ICH Q2R1.

\subsection{Preparation of Solutions}

The solutions below were prepared immediately before use and were protected from light during storage and analysis.

Reference solution (a): $8.0 \mathrm{mg}$ of doxycycline hyclate reference standard was weighed into a $10 \mathrm{ml}$ volumetric flask, $6 \mathrm{ml}$ of $0.01 \mathrm{M}$ hydrochloric acid solution was added, sonicated for $15 \mathrm{~min}$, cooled down to room temperature, and then diluted to mark with $0.01 \mathrm{M}$ hydrochloric acid solution ( $800 \mu \mathrm{g} / \mathrm{ml}$ doxycycline hyclate).

Reference solution (b): $8.0 \mathrm{mg}$ of Metacycline hydrochloride reference standard was weighed into a10 ml volumetric flask, added $6 \mathrm{ml}$ of $0.01 \mathrm{M}$ hydrochloric acid solution, sonicated for $15 \mathrm{~min}$, cooled down toroom temperature, and then diluted to mark with $0.01 \mathrm{M}$ hydrochloric acid solution $(800 \mu \mathrm{g} / \mathrm{ml}$ metacycline hydrochloride).

Reference solution (c): $8.0 \mathrm{mg}$ of 6-epidoxycycline hydrochloride reference standard was weighed into a 10 $\mathrm{ml}$ volumetric flask, $6 \mathrm{ml}$ of $0.01 \mathrm{M}$ hydrochloric acid solution was added, sonicated for $15 \mathrm{~min}$, cooled down to room temperature, and then diluted to mark with $0.01 \mathrm{M}$ hydrochloric acid solution ( $800 \mu \mathrm{g} / \mathrm{ml} \mathrm{6-} \mathrm{epidoxycyc-}$ line hydrochloride).

Reference solution (d): $2.0 \mathrm{mg}$ of 4-epidoxycycline hydrochloride reference standard was weighed into a $10 \mathrm{ml}$ volumetric flask, added $6 \mathrm{ml}$ of $0.01 \mathrm{M}$ hydrochloric acid solution, sonicated for $15 \mathrm{~min}$, cooled down to room temperature, and then diluted to mark with $0.01 \mathrm{M}$ hydrochloric acid solution $(200 \mu \mathrm{g} / \mathrm{ml}$ 4-epidoxycycline hydrochloride).

Reference solution (e): $200 \mu$ from each of the reference solutions (b), (c), and (d) were transferred into a 10 $\mathrm{ml}$ of volumetric flask and diluted to mark $\mathrm{ml}$ with $0.01 \mathrm{M}$ hydrochloric acid solution. $1 \mathrm{ml}$ of the solution was transferred to a $1.8 \mathrm{ml}$ amber HPLC glass vial with pre-slit cap $(16 \mu \mathrm{g} / \mathrm{ml}$ metacycline hydrochloride, $16 \mu \mathrm{g} / \mathrm{ml}$ 6-epidoxycycline hydrochloride, and $4 \mu \mathrm{g} / \mathrm{ml}$ 4-epidoxycycline hydrochloride).

Reference solution (f): $1.6 \mathrm{ml}$ of reference solution (a), $0.4 \mathrm{ml}$ of reference solution (b), $0.6 \mathrm{ml}$ of reference solution (c), and $0.6 \mathrm{ml}$ of reference solution (d) were transferred into a $10 \mathrm{ml}$ of volumetric flask and diluted to mark with $0.01 \mathrm{M}$ hydrochloric acid solution. $1 \mathrm{ml}$ of the solution was transferred to a $1.8 \mathrm{ml}$ amber HPLC glass vial with pre-slit cap $(128 \mu \mathrm{g} / \mathrm{ml}$ doxycycline hyclate, $32 \mu \mathrm{g} / \mathrm{ml}$ metacycline hydrochloride, $48 \mu \mathrm{g} / \mathrm{ml} \mathrm{6-epi-}$ doxycycline hydrochloride, and $12 \mu \mathrm{g} / \mathrm{ml}$ 4-epidoxycycline hydrochloride).

Reference solution (g): $1.6 \mathrm{ml}$ of reference solution (a) was transferred into a $10 \mathrm{ml}$ of volumetric flask and diluted to mark with $0.01 \mathrm{M}$ hydrochloric acid solution. $1 \mathrm{ml}$ of the solution was transferred to a $1.8 \mathrm{ml}$ amber HPLC glass vial with pre-slit cap (128 $\mu \mathrm{g} / \mathrm{ml}$ doxycycline hyclate).

2 M Sodium hydroxide solution: $0.8 \mathrm{~g}$ of sodium hydroxide powder was weighed into a $10 \mathrm{ml}$ volumetric flask. It was vortexed for $1 \mathrm{~min}$ and diluted to mark with water.

0.2 M Sodium hydroxide solution: Sodium hydroxide powder (1.6 g) was weighed into a $200 \mathrm{ml}$ volumetric flask, vortexed for 1 min and diluted to mark with water.

0.01 M Hydrochloric acid solution: $1.1 \mathrm{~g}$ of hydrochloric acid solution (33\%) was weighed into a $1000 \mathrm{ml}$ volumetric flask and was diluted to mark with water.

Phosphate buffer solution (pH 8.0): $27.2 \mathrm{~g}$ of monobasic potassium phosphate dihydrate was weighed into a $1000 \mathrm{ml}$ volumetric flask, dissolved using a horizontal shaker, and diluted to mark with water. $125 \mathrm{ml}$ of the potassium phosphate solution was transferred to a $500 \mathrm{ml}$ volumetric flask, and $125.25 \mathrm{ml}$ of $0.2 \mathrm{M}$ sodium hydroxide was added and then diluted to mark with water.

$1 \%(w / v)$ Tetrabutylammonium hydrogen sulfate solution (pH 8.0): $0.5 \mathrm{~g}$ of tetrabutylammonium hydrogen sulfate was weighed into a $100 \mathrm{ml}$ volumetric flask, and $60 \mathrm{ml}$ of water was added. $0.2 \mathrm{M}$ sodium hydroxide solution was added drop wise while checking $\mathrm{pH}$ with a calibrated $\mathrm{pH}$ meter until the final $\mathrm{pH}$ of $8.0 \pm 0.1$ was 
achieved. It was then diluted to mark with water.

4\% (w/v) Disodium edetate solution (pH 8.0): Disodium edetate ( $2.0 \mathrm{~g}$ ) was weighed into a $50 \mathrm{ml}$ volumetric flask, and dissolved in $40 \mathrm{ml}$ of water. $2 \mathrm{M}$ sodium hydroxide solution was added drop wise while checking with a calibrated $\mathrm{pH}$ meter until the final $\mathrm{pH}$ of $8.0 \pm 0.1$ was achieved. It was then diluted to mark with water.

Mobile Phase: The mobile phase was comprised of 6\% (w/w) of 2-methylpropan-2-ol, 400 ml of phosphate buffer ( $\mathrm{pH} 8.0), 50 \mathrm{ml}$ of $1 \%(\mathrm{w} / \mathrm{v})$ tetrabutylammonium hydrogen sulfate solution $(\mathrm{pH} 8.0)$, and $10 \mathrm{ml}$ of $4 \%$ $(\mathrm{w} / \mathrm{v})$ disodium edetate solution $(\mathrm{pH} 8.0)$ in DI water. The mobile phase was filtered through $0.45 \mu \mathrm{m}$ nylon membrane filters before use.

\subsubsection{Preparation of Standard Stock Solutions}

$10.0 \mathrm{mg}$ of doxycycline hyclate reference standard was weighed and dissolved in a $10 \mathrm{ml}$ volumetric flask and diluted to mark with $0.01 \mathrm{M}$ hydrochloric acid solution to obtain a solution of $1000 \mu \mathrm{g} / \mathrm{ml}$ doxycycline hyclate. It was labelled as Doxycycline Hyclate Stock Solution I with the actual concentration along with the preparation date for the standard curve standards.

$10.0 \mathrm{mg}$ of doxycycline hyclate reference standard was weighed and dissolved in a $10 \mathrm{ml}$ volumetric flask and dilute to mark with $0.01 \mathrm{M}$ hydrochloric acid solution to obtain a solution of $1000 \mu \mathrm{g} / \mathrm{ml}$ doxycycline hyclate. It was labelled as Doxycycline Hyclate Stock Solution II with actual concentration along with the preparation date for the quality control standards.

$1.0 \mathrm{mg}$ of doxycycline hyclate reference standard was weighed and dissolved in a $10 \mathrm{ml}$ volumetric flask and dilute to mark with $0.01 \mathrm{M}$ hydrochloric acid solution to obtain a solution of $100 \mu \mathrm{g} / \mathrm{ml}$ doxycycline hyclate. It was labelled as Doxycycline Hyclate System Suitability Solution with actual concentration along with preparation date for system suitability testing.

\subsubsection{Preparation of Calibration Standards}

The target or nominal value of $100 \%$ for doxycycline hyclate samples was $128 \mu \mathrm{g} / \mathrm{ml}$. A calibration curve for doxycycline hyclate should cover the range 50 to $250 \mu \mathrm{g} / \mathrm{ml}$. Calibration curve standards for doxycycline were prepared by diluting Doxycycline Hyclate Stock Solution I (1000 $\mu \mathrm{g} / \mathrm{ml})$ to 50 and $250 \mu \mathrm{g} / \mathrm{ml}$ in $0.01 \mathrm{M}$ hydrochloric acid solution, as follows:

To five appropriately labeled HPLC glass vials, $50 \mu \mathrm{l}, 75 \mu \mathrm{l}, 100 \mu \mathrm{l}, 150 \mu \mathrm{l}$, and $250 \mu \mathrm{l}$, respectively, of Doxycycline Hyclate Stock Solution I was pipetted. Respective volumes of $0.01 \mathrm{M}$ hydrochloric acid solution was added to each vial to achieve $1 \mathrm{ml}$ total volume $(50 \mu \mathrm{g} / \mathrm{ml}, 75 \mu \mathrm{g} / \mathrm{ml}, 100 \mu \mathrm{g} / \mathrm{ml}, 150 \mu \mathrm{g} / \mathrm{ml}$, and $250 \mu \mathrm{g} / \mathrm{ml}$ final concentrations, respectively). Each vial was caped, and vortexed for $10 \mathrm{~s}$.

Each calibrator was injected at a minimum of two times daily, during three days, to generate a standard calibration curve. Calibration curves were calculated by a weighted or non- weighted linear equation describing the best relationship between doxycycline concentration and the detector response (peak area) of doxycycline using Microsoft Excel. The acceptance criterion for the linearity of the analytical method was $r^{2}>0.99$.

\subsubsection{Quality Control Standards}

Quality control standards ( $n=5$, at each QC level) were prepared daily by making dilutions from Doxycycline Hyclate Stock Solution II $(1000 \mu \mathrm{g} / \mathrm{ml})$ in solvent. Quality control standards were prepared as follows:

Low QC: To each of three HPLC glass vials (labeled Low QC 1 through Low QC 3) $50 \mu$ l of Doxycycline Hyclate Stock Solution II $(1000 \mu \mathrm{g} / \mathrm{ml})$ and $950 \mu \mathrm{l}$ of $0.01 \mathrm{M}$ hydrochloric acid solution was added, to get final concentrations of $50 \mu \mathrm{g} / \mathrm{ml}$ doxycycline. Each vial was capped and vortexed for $10 \mathrm{~s}$.

Mid QC: To each of three HPLC glass vials (labeled Mid QC 1 through Mid QC 3), $100 \mu$ l ofDoxycycline Hyclate Stock Solution II $(1000 \mu \mathrm{g} / \mathrm{ml})$ and $900 \mu \mathrm{l}$ of $0.01 \mathrm{M}$ hydrochloric acid solution was added, to get final concentrations of $100 \mu \mathrm{g} / \mathrm{ml}$ doxycycline. Each vial was capped and vortexed for $10 \mathrm{~s}$.

High QC: To each of three HPLC glass vials (labeled High QC 1 through High QC 3) $250 \mu$ l of Doxycycline Hyclate Stock Solution II $(1000 \mu \mathrm{g} / \mathrm{ml})$ was added and $750 \mu \mathrm{l}$ of $0.01 \mathrm{M}$ hydrochloric acid solution was added, to get final concentrations of $250 \mu \mathrm{g} / \mathrm{ml}$ doxycycline. Each vial was capped and vortexed for $10 \mathrm{~s}$.

Three injection of each low, middle, and high quality control standard were analyzed once for doxycycline ( $n$ = 9 total injections) according to the ICH Q2 (R1) Analytical Method Validation. The mean, standard deviation (SD) and relative standard deviation (RSD) are calculated for peak area, and resulting concentration for determination of precision and accuracy. For doxycycline quality control standards the \%RSD of peak area response 
units was not to exceed 5.0\%, at each concentration level. For doxycycline quality control standards the \%RSD of accuracy was not to exceed $15.0 \%$, at the low QC level and $10.0 \%$ at the intermediate and high QC levels. For doxycycline quality control standards the \%RSD of precision was not to exceed $5.0 \%$, at each concentration level.

\subsubsection{Preparation of Test Solutions}

Test solution (a): 20 capsules of doxycycline hyclate were weighed; the capsule shells were carefully opened and transferred the powder into a vial. A quantity of the contents of the capsules containing the equivalent of 7.0 $\mathrm{mg}$ anhydrous doxycycline was weighed into a $15 \mathrm{ml}$ centrifuge tube, added $10 \mathrm{ml}$ of 0.01 M hydrochloric acid solution, vortexed for $10 \mathrm{~s}$, placed on a horizontal shaker for $10 \mathrm{~min}$, sonicated for $5 \mathrm{~min}$, and then centrifuged for $10 \mathrm{~min}$ at $1000 \mathrm{~g}$. Approximately $2 \mathrm{ml}$ of the supernatant was taken with a syringe and filtered through 0.45 $\mu \mathrm{m}$ PTFE syringe filter to a $1.8 \mathrm{ml}$ amber HPLC glass vial with pre-slit cap. This extraction procedure was performed immediately before use $(700 \mu \mathrm{g} / \mathrm{ml}$ doxycycline).

Test solution (b): The powder prepared for test solution (a) was used. A quantity of the contents of the capsules containing the equivalent of $17.5 \mathrm{mg}$ anhydrous doxycycline was weighed into a $50 \mathrm{ml}$ centrifuge tube, added $25 \mathrm{ml}$ of $0.01 \mathrm{M}$ hydrochloric acid solution, vortexed for $10 \mathrm{~s}$, place on a horizontal shaker for 10 min, sonicated for $5 \mathrm{~min}$, and then centrifuged for $10 \mathrm{~min}$ at $1000 \mathrm{~g}$. $4 \mathrm{ml}$ of the supernatant was transferred to a 25 $\mathrm{ml}$ volumetric flask and dilute to mark with the same solvent, vortexed for $10 \mathrm{~s}$. Approximately $2 \mathrm{ml}$ of the solution was taken and filtered through $0.45 \mu \mathrm{m}$ PVDF syringe filter to $1.8 \mathrm{~m}$ amber HPLC vial with pre-slit cap. This extraction procedure was performed immediately before use (112 $\mu \mathrm{g} / \mathrm{ml}$ doxycycline).

The reference solutions were stored in covered sealed flasks at $5^{\circ} \mathrm{C}$, and were kept away from direct light.

\section{Results and Discussion}

\subsection{Evaluation of the Chromatographic Method and the Columns}

Several polystyrene-divinylbenzene columns from different brands were tested in order to compare the influence of different PSDVB packing materials from various vendors on the chromatographic separation of doxycycline analogues. The optimum retention time of the analytes which was observed using the Agilent PLPR-S column with $250 \mathrm{~mm}$ length and $8 \mu \mathrm{m}$ particle size was $8.3 \mathrm{~min}$ for 4-epidoxycycline, $10.5 \mathrm{~min}$ for metacycline, 12.8 min for 6-epidoxycycline, and 17.8 min for doxycycline.

It was also observed that doxycycline and its impurities have two maximum ultraviolet absorption wavelengths: first $\lambda_{\max }$ between 245 and $255 \mathrm{~nm}$, and the second $\lambda_{\max }$ between 355 and $365 \mathrm{~nm}$. However, the background absorbance was significantly higher below $270 \mathrm{~nm}$, for example, at $254 \mathrm{~nm}$ resulting in significant noise in the baseline signal. Since ultraviolet absorptivities of some analytes were not strong enough to provide sufficient sensitivity above $355 \mathrm{~nm}, 270 \mathrm{~nm}$ was chosen as the detection wavelength in this study, which provided a smoother baseline (data not shown). Despite these observations, we noticed that in some compendial monographs $254 \mathrm{~nm}$ was still used as the detection wavelength [16] [17].

The highest column efficiency and superior resolution were obtained with Agilent's PLRP-S columns (Figure 1 and Table 2). The Agilent PLPR-S column with $250 \mathrm{~mm}$ length and $8 \mu \mathrm{m}$ particle size provided the best performance characteristics which included enhanced resolution, greater chromatographic efficiency, and efficient analysis run time. Comparable results were obtained with the same manufacturer's column with $5 \mu \mathrm{m}$ particle size but the former was found to be more efficient in terms of peak performance and total run time. However, Agilent PLPR-S column with $150 \mathrm{~mm}$ length and $3 \mu \mathrm{m}$ particle size did not provide adequate resolution and peak performance. Based on the performances of the columns with 5 and $8 \mu \mathrm{m}$ particle size, a better separation was anticipated, as per van Deemter equation, which led to the development of sub-2 $\mu \mathrm{m}$ particle size ultra-high performance liquid chromatography (UPLC) columns [23].

This indicates that the drug sorbent interaction may be more important than the particle size or specific surface area of the column particles, especially since the pore size of all columns was 10 nanometers. No separation was obtained using the Waters Styragel column, most probably, as per manufacturer's technical information sheet the Styragel columns are mainly designed for gel permeation chromatography and may not be suitable for the current chromatographic conditions and analytes [24]. A similar situation was observed with Phenomenex Phenogel column. The Hamilton PRP-1 column produced relatively better results yet we observed poor resolution, as previously described by Dihuidi et al. [18] (Figure 2). 
Table 2. System suitability test results.

\begin{tabular}{|c|c|c|c|c|c|c|c|c|c|c|c|c|c|}
\hline \multirow{2}{*}{ USP Criteria } & \multirow{2}{*}{ Specification } & \multicolumn{3}{|c|}{ Doxycycline } & \multicolumn{3}{|c|}{ Metacycline } & \multicolumn{3}{|c|}{ 6-epidoxycycline } & \multicolumn{3}{|c|}{ 4-epidoxycycline } \\
\hline & & Day 1 & Day 2 & Day3 & Day 1 & Day 2 & Day 3 & Day 1 & Day 2 & Day 3 & Day 1 & Day 2 & Day 3 \\
\hline Retention time & $\mathrm{RSD}<2.0 \%$ & 0.1 & 0.2 & 0.1 & 0.1 & 0.2 & 0.1 & 0.1 & 0.1 & 0.1 & 0.5 & 0.1 & 0.1 \\
\hline Capacity factor & $>1.0$ & 5.9 & 5.9 & 6.1 & 3.2 & 3.2 & 3.3 & 4.1 & 4.1 & 4.3 & 2.4 & 2.3 & 2.4 \\
\hline Symmetry & $>0.5$ & 1.0 & 1.0 & 1.0 & 1.0 & 1.0 & 1.0 & 1.1 & 1.1 & 1.0 & 1.0 & 1.0 & 1.0 \\
\hline Area & $\mathrm{RSD}<2.0 \%$ & 0.7 & 0.9 & 0.4 & 1.4 & 0.3 & 0.2 & 1.3 & 0.1 & 0.2 & 0.9 & 1.9 & 1.1 \\
\hline Theoretical plates/meter & $>2000$ & 3969 & 3730 & 3533 & 12,160 & 10,438 & 9887 & 14,842 & 12,910 & 11,904 & 5201 & 4549 & 4352 \\
\hline USP Tailing & $<2.0$ & 1.0 & 1.0 & 1.0 & 1.0 & 1.0 & 1.0 & 1.1 & 1.1 & 1.0 & 1.1 & 1.0 & 1.0 \\
\hline Resolution & $>2.0$ & 2.9 & 2.8 & 2.8 & 2.5 & 2.4 & 2.4 & 2.9 & 2.7 & 2.6 & 3.3 & 2.9 & 2.8 \\
\hline
\end{tabular}

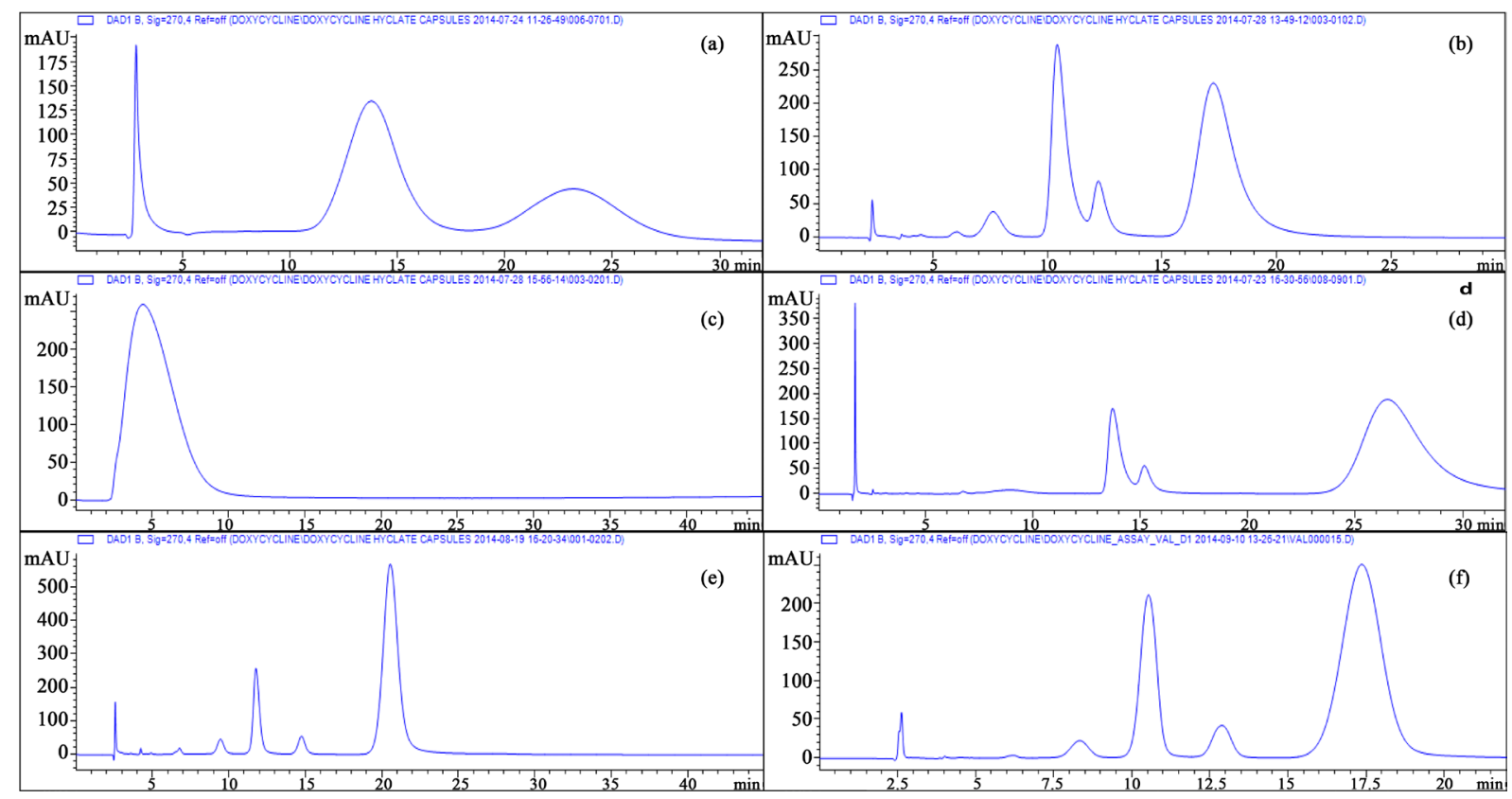

Figure 2. The chromatograms of the Reference Solution (f) using different columns: (a) Phenomenex Phenogel $300 \times 4.6$ mm, $5 \mu \mathrm{m}$; (b) Hamilton PRP-1 $250 \times 4.6$ mm, $5 \mu \mathrm{m}$; (c) Waters Styragel HR 0.5 DMF $300 \times 4.6$ mm, $5 \mu$ m; (d) Agilent PLPR-S $150 \times 4.6$ mm, 3 m; (e) Agilent PLPR-S $250 \times 4.6$ mm, $5 \mu \mathrm{m}$; (f) Agilent PLPR-S $250 \times 4.6$ mm, $8 \mu \mathrm{m}$.

The mobile phase plays an important role in the chromatographic performance of the respective columns. As per our observations, using an alkali mobile phase has several disadvantages when applied to this compendial method: 1) alkali pH of the mobile phase could trigger the formation of isomeric analogues [25]; 2) chelating agents, such as EDTA, are needed in the mobile phase to increase column efficiency because support surface of tetracyclines is fully activated at alkali $\mathrm{pH}$ [21]; tetrabutylammonium hydrogen sulfate, an ion-pair agent, is used to reduce peak tailing due to ionized nature of the analytes at higher $\mathrm{pH}$, which may cause a less robust method, longer equilibration and run times along with shorter column life [6] [19]. However, more acidic conditions could result in significantly increased retention times due to the possible hydrophobic interactions between the column and the analytes.

Repeatability of peak areas and peak retention times, peak symmetries and tailings, capacity factors and resolution of the peaks were found to be acceptable as per United States Pharmacopeia and British Pharmacopoeia recommendations (Table 2). As expected, the number of theoretical plates was relatively low but still sufficient to meet the minimum USP specification as it is known that tetracyclines generate low theoretical plates, especially with PSDVB columns [14]. A representative chromatogram of reference solution (f) is shown in Figure 3. 


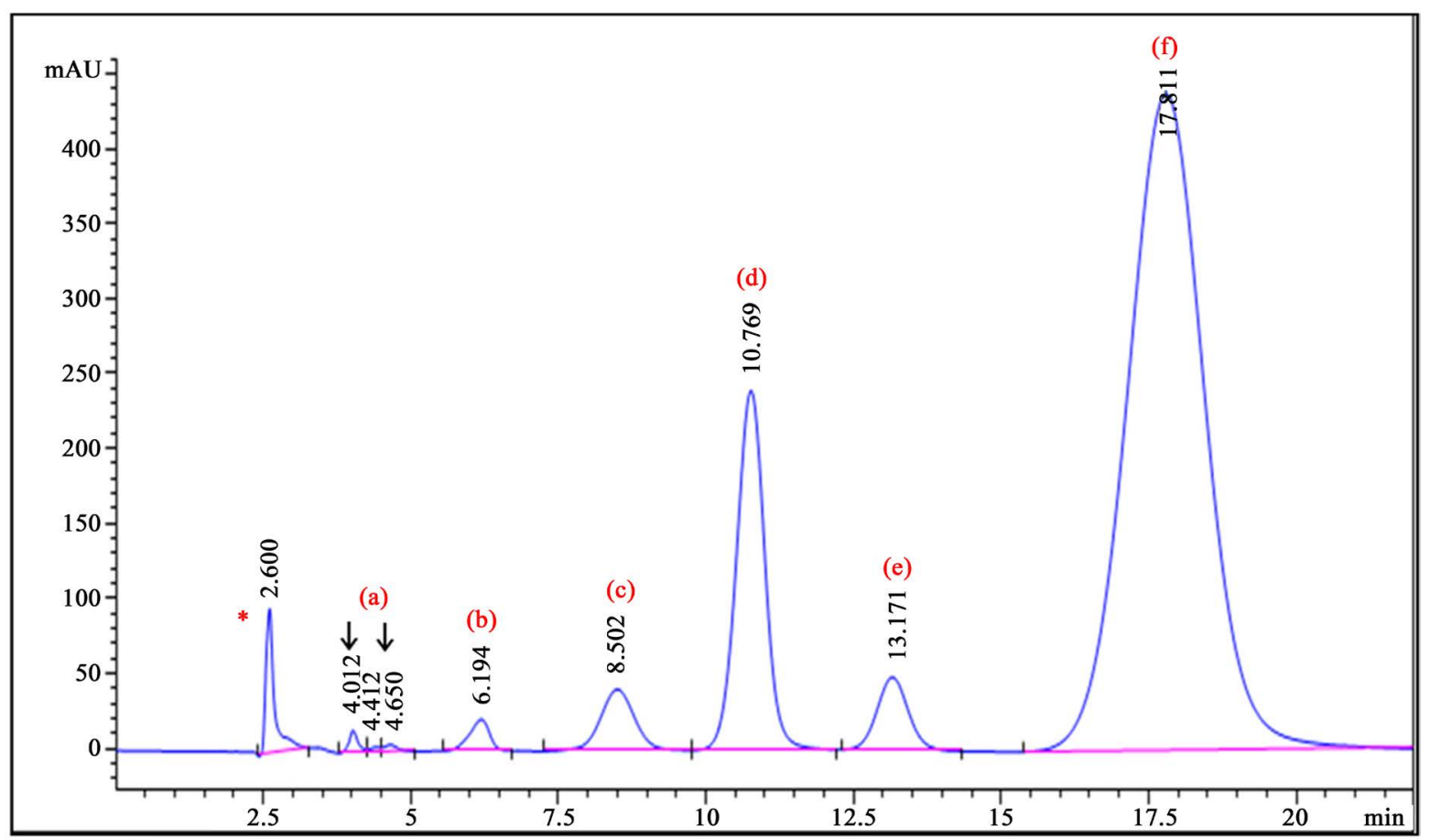

Figure 3. The chromatogram of the Reference Solution (f): (a) and (b): unknown impurities ${ }^{1}$; (c): 4-epidoxycycline; (d): metacycline HCl; (e): 6-epidoxycycline; (f): doxycycline hyclate (Note ${ }^{*}=$ impurity in the blank, 1 = study to determine the impurities $(a)$ and $(b)$ is currently underway).

\subsection{Validation}

The analytical method for doxycycline was validated according to the requirements of United States Pharmacopeia and the method was found to be specific, accurate, precise, and linear over the analytical range of 50 $250 \mu \mathrm{g} / \mathrm{mL}$.

\subsubsection{Precision and Accurancy}

The method's accuracy and precision were evaluated by using three different quality control standard concentrations over the analytical range, during three consecutive days. Inter- and intra-day \%RSD values were found to be lower than $5 \%$, as well as \%recovery values during the experiments, thereby establishing the method's accuracy and precision over the analytical range (Table 3).

\subsubsection{Linearity and Range}

Linearity and range of the method were determined over three consecutive days and the range was established by demonstrating acceptable accuracy, precision and linearity over the analytical range of $50-250 \mu \mathrm{g} / \mathrm{mL}$ (Table 4).

\subsubsection{Drug Product Evaluation}

Two batches of doxycycline capsules were tested for assay and impurity content (Table 5). The tested doxycycline drug products are within the BP/USP specifications with regards to their assay and impurity contents.

\section{Conclusions}

This study showed that the use of different polystyrene-divinylbenzene columns for the determination of doxycycline hyclate might result in significantly different outcomes, depending further on the packing material characteristics of the column which were mainly determined by the column manufacturer. Since the compendia allow for adjustments to the chromatographic method, a more specific definition of the column characteristics should be given in the compendial monograph in order to ensure that the method can be reproduced efficiently. 
Table 3. Accuracy, repeatability and intermediate precision of the analytical method.

\begin{tabular}{|ccccc}
\hline & & \multicolumn{3}{c}{ Validation solutions $(\mu \mathrm{g} / \mathrm{ml})$} \\
\hline & & 50 & 100 & 250 \\
Accuracy (\% recovery) & Day 1 & 95.1 & 95.4 & 95.6 \\
& Day 2 & 99.1 & 102.3 & 102.4 \\
& Day 3 & 99.7 & 99.6 & 101.1 \\
Precision (\% RSD) & Day 1 & 2.4 & 0.5 & 0.9 \\
& Day 2 & 3.6 & 2.2 & 0.2 \\
& Day 3 & 4.8 & 0.6 & 0.9 \\
& Intermediate & 3.9 & 3.3 & 3.2 \\
\hline
\end{tabular}

Table 4. Linearity of the analytical method.

\begin{tabular}{cccccc}
\hline Standard curve & Analytical range $(\mu \mathrm{g} / \mathrm{ml})$ & Calibrators & Slope & $y$-intercept & $R^{2}$ value \\
\hline Day 1 & $50-250$ & 5 & 191.78 & -225.67 & 0.9997 \\
Day 2 & $50-250$ & 5 & 195.70 & -429.58 & 0.9999 \\
Day 3 & $50-250$ & 5 & 197.43 & -256.66 & 1 \\
\hline
\end{tabular}

Table 5. Test results for doxycycline hyclate capsule assay and impurities.

\begin{tabular}{cccc}
\hline Test & Specifications & Batch I & Batch II \\
Assay & $95 \%-105 \%$ asper BP & $106.5 \%$ & $105.7 \%$ \\
4-epidoxycycline & $90 \%-120 \%$ asper USP & $0.14 \%$ & $0.13 \%$ \\
Metacycline & $<0.5 \%{ }^{*}$ & $0.66 \%$ & $0.15 \%$ \\
6-epidoxycycline & $<2 \%$ & $1.15 \%$ & $1.12 \%$ \\
Maximum unknown impurity & $<2 \%$ & ND $^{* *}$ & ND $^{* *}$ \\
Total impurities & $<0.5 \%$ & $1.95 \%$ & $1.39 \%$ \\
\hline
\end{tabular}

*Although there is no specific limit in the BP or USP, it was considered as an unknown impurity and evaluated accordingly;

${ }^{* *}$ N/A: Not available; ND: Not detected.

However, the significant differences in the nature of the co-polymer divinylbenzene packing did not allow for adjustments to the column method to resolve doxycycline or its impurities for all the L21 columns tested. In summary, the efficient implementation of compendial methods using divinylbenzene co-polymer HPLC columns for large complex molecules like doxycycline will require a more comprehensive understanding of the nature of the polymer packing and clearly defined specifications of the polymer.

In conclusion, a simple and efficient compendial method for HPLC was modified according to USP <621> and was implemented and validated for doxycycline assay and impurities. The method addressed each of the analytical validation characteristics such as accuracy, precision, specificity, linearity, and range, and met the USP acceptance criteria. The usefulness of this method was demonstrated by its efficient implementation and successful application for the analysis of doxycycline hyclate drug products for assay and impurities.

\section{Acknowledgements}

This project was supported in part by a fellowship appointment to the Research Participation Program at the Center for Drug Evaluation and Research administered by the Oak Ridge Institute for Science and Education (ORISE) through an interagency agreement between the U.S. Department of Energy and the U.S. Food and Drug Administration. The authors wish to thank Gretchen Whitesell, Sarah Mirza and Bryan Lowry for their technical assistance.

\section{References}

[1] Jantratid, E., Strauch, S., Becker, C., Dressman, J.B., Amidon, G.L., Junginger, H.E., Kopp, S., Midha, K.K., Shah, V.P., Stavchansky, S. and Barends, D.M. (2010) Biowaiver Monographs for Immediate Release Solid Oral Dosage Forms: Doxycycline Hyclate. Journal of Pharmaceutical Sciences, 99, 1639-1653.

[2] Shariati, S., Yamini, Y. and Esrafili, A. (2009) Carrier Mediated Hollow Fiber Liquid Phase Microextraction Com- 
bined with HPLC-UV for Preconcentration and Determination of Some Tetracycline Antibiotics. Journal of Chromatography B, 877, 393-400. http://dx.doi.org/10.1016/j.jchromb.2008.12.042

[3] Mack, G.D. and Ashworth, R.B. (1978) A High Performance Liquid Chromatographic System for the Analysis of Tetracycline Drug Standards, Analogs, Degradation Products and Other Impurities. Journal of Chromatographic Science, 16, 93-101. http://dx.doi.org/10.1093/chromsci/16.3.93

[4] Oka, H., Ikai, Y., Kawamura, N., Uno, K., Yamada, M., Harada, K. and Suzuki, M. (1987) Improvement of Chemical Analysis of Antibiotics: XII. Simultaneous Analysis of Seven Tetracyclines in Honey. Journal of Chromatography A, 400, 253-261. http://dx.doi.org/10.1016/S0021-9673(01)81619-8

[5] Oka, H., Ikai, Y., Kawamura, N., Uno, K., Yamada, M., Harada, K., Uchiyama, M., Asukabe, H. and Suzuki, M. (1987) Improvement of Chemical Analysis of Antibiotics. X. Determination of Eight Tetracyclines Using Thin-Layer and High-Performance Liquid Chromatography. Journal of Chromatography, 393, 285-296.

[6] Ding, X.J. and Mou, S.F. (2000) Ion Chromatographic Analysis of Tetracyclines Using Polymeric Column and Acidic Eluent. Journal of Chromatography A, 897, 205-214. http://dx.doi.org/10.1016/S0021-9673(00)00779-2

[7] Seth, P. and Stamm, A. (1986) Quantitative Estimation and Separation of Doxycycline HCl and Its Related Products. Drug Development and Industrial Pharmacy, 12, 1469-1475. http://dx.doi.org/10.3109/03639048609065871

[8] Pesek, J.J. and Matyska, M.T. (1996) Separation of Tetracyclines by High-Performance Capillary Electrophoresis and Capillary Electrochromatography. Journal of Chromatography A, 736, 313-320. http://dx.doi.org/10.1016/0021-9673(95)01316-4

[9] Kazemifard, A.G. and Moore, D.E. (1997) Evaluation of Amperometric Detection for the Liquid-Chromatographic Determination of Tetracycline Antibiotics and Their Common Contaminants in Pharmaceutical Formulations. Journal of Pharmaceutical and Biomedical Analysis, 16, 689-696. http://dx.doi.org/10.1016/S0731-7085(97)00089-7

[10] Zhao, F.N., Zhang, X.Z. and Gan, Y.R. (2004) Determination of Tetracyclines in Ovine Milk by High-Performance Liquid Chromatography with a Coulometric Electrode Array System. Journal of Chromatography A, 1055, 109-114. http://dx.doi.org/10.1016/j.chroma.2004.08.131

[11] Skulason, S., Ingolfsson, E. and Kristmundsdottir, T. (2003) Development of a Simple HPLC Method for Separation of Doxycycline and Its Degradation Products. Journal of Pharmaceutical and Biomedical Analysis, 33, 667-672. http://dx.doi.org/10.1016/S0731-7085(03)00316-9

[12] Yekkala, R., Diana, J., Adams, E., Roets, E. and Hoogmartens, J. (2003) Development of an Improved Liquid Chromatographic Method for the Analysis of Doxycycline. Chromatographia, 58, 313-316.

[13] Kogawa, A.C. and Salgado, H.R.N. (2012) Doxycycline Hyclate: A Review of Properties, Applications and Analytical Methods. International Journal of Life Science and Pharma Research, 2, 11-25.

[14] Hoogmartens, J., Khan, N.H., Vanderhaeghe, H., Vanderleeden, A.L., Oosterbaan, M., Veldtulp, G.L., Plugge, W., Vandervlies, C., Mialanne, D., Melamed, R. and Miller, J.H.M. (1989) A Collaborative Study of the Analysis of Doxycycline Hyclate by High-Performance Liquid Chromatography on Polystyrene-Divinylbenzene Packing Materials. Journal of Pharmaceutical and Biomedical Analysis, 7, 601-610. http://dx.doi.org/10.1016/0731-7085(89)80226-2

[15] USP37-NF32 (2014) United States Pharmacopeia 37: National Formulary 32.

[16] EP8.0 (2014) European Pharmacopoeia 8.0.

[17] BP (2014) British Pharmacopoeia 2014.

[18] Dihuidi, K., Kucharski, M.J., Roets, E., Hoogmartens, J. and Vanderhaeghe, H. (1985) Quantitative-Analysis of Doxycycline and Related Substances by High-Performance Liquid Chromatography. Journal of Chromatography A, 325, 413-424. http://dx.doi.org/10.1016/S0021-9673(00)96051-5

[19] Young, J.E., Matyska, M.T., Azad, A.K., Yoc, S.E. and Pesek, J.J. (2013) Separation Differences among Phenyl Hydride, Udc Cholesterol, and Bidentate C8 Stationary Phases for Stability Indicating Methods of Tetracyclines. Journal of Liquid Chromatography \& Related Technologies, 36, 926-942.

[20] De Leenheer, A.P. and Nelis, H.J. (1977) Reversed-Phase High-Performance Liquid Chromatography of Doxycycline. Journal of Chromatography A, 140, 293-299. http://dx.doi.org/10.1016/S0021-9673(00)93594-5

[21] Pilorz, K. and Choma, I. (2004) Isocratic Reversed-Phase High-Performance Liquid Chromatographic Separation of Tetracyclines and Flumequine Controlled by a Chaotropic Effect. Journal of Chromatography A, 1031, 303-305. http://dx.doi.org/10.1016/j.chroma.2003.12.024

[22] Naidong, W., Verresen, K., Busson, R., Roets, E. and Hoogmartens, J. (1991) Isolation of Doxycycline, 6-Epidoxycycline and 2-Acetyl-2- Decarboxamidometacycline from Commercial Metacycline by Preparative Column Liquid Chromatography on Silica Gel. Journal of Chromatography A, 586, 67-72. http://dx.doi.org/10.1016/0021-9673(91)80026-D

[23] Tylova, T., Kamenik, Z., Flieger, M. and Olsovska, J. (2011) Comparison of LC Columns Packed with 2.6 mu m 
Core-Shell and Sub-2 mu m Porous Particles for Gradient Separation of Antibiotics. Chromatographia, 74, 19-27. http://dx.doi.org/10.1007/s10337-011-2021-7

[24] Waters (2014) Waters Corporation. http://www.waters.com/webassets/cms/support/docs/WAT044491.pdf

[25] Monser, L. and Darghouth, F. (2000) Rapid Liquid Chromatographic Method for Simultaneous Determination of Tetracyclines Antibiotics and 6-Epi-Doxycycline in Pharmaceutical Products Using Porous Graphitic Carbon Column. Journal of Pharmaceutical and Biomedical Analysis, 23, 353-362. http://dx.doi.org/10.1016/S0731-7085(00)00329-0 